\title{
Factors associated with emergency department visits due to acute asthma
}

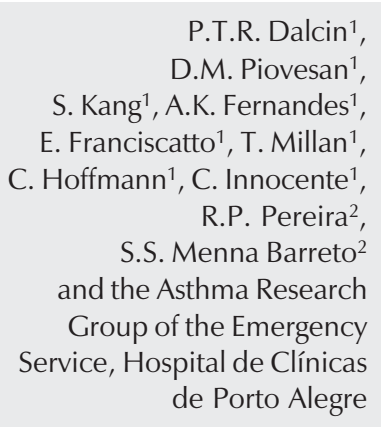

P.T.R. Dalcin ${ }^{1}$,

D.M. Piovesan ${ }^{1}$,

S. Kang ${ }^{1}$, A.K. Fernandes ${ }^{1}$,

E. Franciscatto ${ }^{1}$, T. Millan ${ }^{1}$,

C. Hoffmann ${ }^{1}$, C. Innocente ${ }^{1}$, R.P. Pereira ${ }^{2}$, S.S. Menna Barreto ${ }^{2}$ and the Asthma Research Group of the Emergency Service, Hospital de Clínicas de Porto Alegre

\author{
${ }^{1}$ Serviço de Emergência and ${ }^{2}$ Serviço de Pneumologia, \\ Hospital de Clínicas de Porto Alegre, \\ Departamento de Medicina Interna, \\ Faculdade de Medicina, \\ Universidade Federal do Rio Grande do Sul, \\ Porto Alegre, RS, Brasil
}

\author{
Correspondence \\ P.T.R. Dalcin \\ Rua Honório Silveira Dias, 1529/901 \\ 90540-070 Porto Alegre, RS \\ Brasil \\ Fax: +55-51-3330-0521 \\ E-mail: pdalcin@terra.com.br \\ Research partially supported \\ by FAPERGS.
}

Received August 22, 2003

Accepted April 19, 2004

\begin{abstract}
It is important to identify characteristics related to poor disease control and frequent visits to the emergency department (ED). The objective of the present study was to compare the characteristics of patients attending the adult ED for treatment of asthma exacerbation with those attending an asthma specialist clinic (AC) in the same hospital, and to determine the factors associated with frequent visits to the ED. We conducted a cross-sectional survey of consecutive patients (12 years and older) attending the $\mathrm{ED}(\mathrm{N}=86)$ and the AC $(N=86)$. Significantly more ED patients than AC patients reported ED visits in the past year (95.3 vs 48.8\%; P < $0.001)$ and had difficulty performing work $(81.4 v s 49.4 \%$; $\mathrm{P}<0.001$. Significantly more AC than ED patents had been treated with inhaled corticosteroids (75.6 vs 18.6\%; $\mathrm{P}<0.001)$ used to increase or start steroid therapy when an attack was perceived (46.5 vs $20.9 \% ; \mathrm{P}<0.001)$ and correctly used a metered-dose inhaler $(50.0 \mathrm{vs}$ $11.6 \% ; \mathrm{P}<0.001$ ). The history of hospital admissions (odds ratio, $\mathrm{OR}, 4.00)$ and use of inhaled corticosteroids (OR, 0.27) were associated with frequent visits to the ED. In conclusion, ED patients were more likely than AC patients to be dependent on the acute use of the ED, were significantly less knowledgeable about asthma management and were more likely to suffer more severe disease. ED patients should be considered an important target for asthma education. Facilitating the access to ambulatory care facilities might serve to reduce asthma morbidity.
\end{abstract}

\section{Introduction}

Acute asthma is a very common medical emergency and remains a frequent cause of presentation to emergency departments (ED)
Key words

- Asthma

- Acute exacerbation

- Emergency medicine

- Emergency room visits .................. 
to poor disease control and frequent visits to the ED in order to apply appropriate clinical management (5). Unfortunately, few data are available about the characteristics of those who rely on ED care for acute episodes of asthma (1).

In a recent study (6) we compared the characteristics of patients who frequented the adult ED of Hospital de Clínicas de Porto Alegre (HCPA) with acute asthma. We concluded that a substantial proportion of the patients who visit the ED (51.2\%) are frequent visitors. These patients are more likely to have had at least one hospital admission in the previous year, to use a home nebulizer and to lack a written asthma action plan. They should be considered the most important target for asthma education.

Hanania et al. (5) compared the demographic characteristics of patients attending the ED of a teaching hospital for treatment of acute asthma with those attending an ambulatory care asthma center in the same hospital for the same complaint and concluded that a subgroup of asthmatics depends primarily on crisis-oriented care for the management of asthma.

There is also evidence that patients, especially those whose disease is poorly controlled, benefit from facilitated referrals to specialists. The provision of efficient asthma education can also significantly reduce the risk of health care use, including unscheduled physician visits, ED visits, and admissions to hospital for acute asthma (7).

The objective of the present study was to compare the clinical characteristics of patients attending the adult ED of a teaching hospital for treatment of an acute asthma exacerbation with those attending an asthma specialist outpatient clinic (AC) in the same hospital for treatment of non-urgent asthma. A second purpose of the study was to determine the factors associated with frequent visits to the ED in these two groups of patients.

\section{Material and Methods}

\section{Study design}

We conducted a cross-sectional survey of consecutive patients (12 years and older) who frequented the adult ED for the treatment of asthma exacerbation and at the outpatient asthma care facility. The study was performed at the HCPA (a large, tertiary care, university-affiliated hospital). The data for the ED group were collected between September and October 2001 and the data for the AC group were collected between March and October 2002. Patients were included in the AC group until they corresponded to the same sample size as the ED group.

The protocol was reviewed and approved by the Ethics and Research Committee of the HCPA, and written informed consent to participate in the study was obtained from patients or their parents.

\section{Subjects}

Patients were eligible to participate if they had a clinical diagnosis of asthma as defined by the American Thoracic Society guidelines (8) and were 12 years or older. An exacerbation in asthma was defined by an increase in wheezing and/or dyspnea. Patients were excluded if the primary reason for the ED visit was not acute asthma.

Patients were excluded if they suffered from other chronic respiratory illnesses. Patients were enrolled only once in the study.

\section{Measures and procedures}

All patients were assessed by a member of the study team. Patients who consented to participate answered a questionnaire applied by a member of the study team while in the ED or in the routine AC. Data were collected regarding demographic characteristics, socioeconomic status, the attack that led to the 
current visit, asthma-related morbidity, regular medications, past medical history, asthma management plan, patient behavior, and the correct handling of a metered-dose inhaler (MDI). Each patient's skill in using an MDI was assessed by the project member using a five-item observational check list containing the important steps in using this device (5).

\section{Statistical analysis}

All analyses were performed using the SPSS 10.0 software. Data were summarized using proportion, mean \pm standard deviation, and median with interquartile. Univariate analysis was performed using the chi-square test, Student $t$-test, and Wilcoxon rank sum test where appropriate. Results were considered significant at $\mathrm{P}<0.05$. Univariate analysis was used to compare the ED group with the AC group. We also performed a separate univariate analysis for the dependent variables of 1) patients with 2 or more ED visits in the last year, 2) patients with 3 or more ED visits in the last year and 3) patients with 4 or more ED visits in the last year. Variables that were significant $(\mathrm{P}<0.05)$ at two-tailed univariate analysis were evaluated for inclusion in a multivariate logistic regression analysis which yielded an odds ratio and $95 \%$ confidence interval for each factor in the model. All $\mathrm{P}$ values were two sided, with $\mathrm{P}<$ 0.05 being considered statistically significant.

\section{Results}

Eighty-six patients who frequented the adult ED for treatment of acute asthma over a period of two months and 86 patients who went to the AC over a period of 8 months were evaluated for recruitment, and all were included in the study.

The demographic characteristics and socioeconomic status of the population are shown in Table 1. Most patients $(70.9 \%)$ were females and white $(75.0 \%)$. The ED group was younger than the AC group (45.6 \pm 18.5 vs $38.4 \pm 18.3$ years, respectively; $\mathrm{P}$ $=0.03)$. The two groups did not differ regarding other demographic characteristics or socioeconomic status.

The data about asthma morbidity, regular use of medications and past medical history are presented in Table 2 . Significantly more ED patients reported previous ED visits compared with AC patients in the past year ( 95.3 vs $48.8 \%$, respectively; $\mathrm{P}<0.001)$ and in the past month (58.1 vs $12.8 \%$, respectively; $\mathrm{P}$ $<0.001)$. Eighty-one percent of ED patients had difficulty performing work or other activities as a result of asthma in the past month compared with $49 \%$ of AC patients (P $<0.001)$. There was a higher rate of days of

Table 1. Demographic characteristics and socioeconomic status of the asthmatic patients studied here.

\begin{tabular}{|c|c|c|c|}
\hline Variable & $\begin{array}{c}\text { Total } \\
(\mathrm{N}=172)\end{array}$ & $\begin{array}{l}\text { Emergency } \\
\text { room patients } \\
(\mathrm{N}=86)\end{array}$ & $\begin{array}{c}\text { Asthma } \\
\text { specialist } \\
\text { clinic patients } \\
(\mathrm{N}=86)\end{array}$ \\
\hline \multicolumn{4}{|l|}{ Sex, \% } \\
\hline Female & 70.9 & 70.9 & 70.9 \\
\hline Male & 29.1 & 29.1 & 29.1 \\
\hline Age, years (mean $\pm S D$ ) & $45.6 \pm 18.5$ & $38.4 \pm 18.3$ & $52.8 \pm 15.7^{*}$ \\
\hline \multicolumn{4}{|l|}{ Race, \% } \\
\hline White & 75.0 & 70.9 & 79.1 \\
\hline Black & 19.2 & 19.8 & 18.6 \\
\hline Other & 5.8 & 9.3 & 2.3 \\
\hline \multicolumn{4}{|l|}{ Marital status, \% } \\
\hline With a partner & 53.0 & 45.1 & 60.5 \\
\hline Without a partner & 47.0 & 54.9 & 39.5 \\
\hline Living alone, \% & 14.0 & 14.0 & 14.0 \\
\hline Educational level, \% Illiterate & 3.6 & 7.1 & 0 \\
\hline$\leq 8$ years of school & 65.5 & 60.7 & 70.2 \\
\hline$>9$ years of school and <high school & ol 24.4 & 27.4 & 21.4 \\
\hline Higher education ( $\geq$ high school) & 5.4 & 4.8 & 6.0 \\
\hline \multicolumn{4}{|l|}{ Income level per annum, \% } \\
\hline$<R \$ 2500$ & 26.5 & 27.4 & 25.6 \\
\hline$R \$ 2500-12000$ & 40.0 & 42.9 & 37.2 \\
\hline$>R \$ 12000$ & 33.5 & 29.8 & 37.2 \\
\hline \multicolumn{4}{|l|}{ Job availability, \% } \\
\hline Employed & 29.9 & 30.9 & 29.1 \\
\hline Unemployed & 70.1 & 69.1 & 70.9 \\
\hline Sick leave benefits, \% & 15.7 & 16.3 & 15.1 \\
\hline Living in a city, $\%$ & 91.9 & 95.3 & 88.4 \\
\hline $\begin{array}{l}\text { Avoidance of asthma medications } \\
\text { due to cost concerns, } \%\end{array}$ & 53.5 & 50.0 & 57.0 \\
\hline
\end{tabular}

${ }^{*} \mathrm{P}<0.05$ compared to emergency department patients (chi-square test for categorical variables and Student $t$-test for continuous variables). 
disability for ED patients compared with AC patients in the past year (median 11 vs 2, respectively; $\mathrm{P}<0.001)$ and in the past month (median 3 vs 0 , respectively; $\mathrm{P}<$ 0.001). Significantly more AC patients had been treated with a regular inhaled corticosteroid than ED patients during the preceding year $(75.6$ vs $18.6 \%$; $\mathrm{P}<0.001)$. Significantly more ED patients had been treated with

Table 2. Asthma morbidity, regular medications and past medical history.

\begin{tabular}{|c|c|c|}
\hline Variable & $\begin{array}{l}\text { Emergency } \\
\text { room patients } \\
(\mathrm{N}=86)\end{array}$ & $\begin{array}{c}\text { Ambulatory } \\
\text { patients } \\
(\mathrm{N}=86)\end{array}$ \\
\hline \multicolumn{3}{|l|}{ ED visits, \% yes } \\
\hline In the past year & 95.3 & $48.8^{*}$ \\
\hline In the past month & 58.1 & $12.8^{*}$ \\
\hline \multicolumn{3}{|l|}{ Frequency of ED visits in the past year, $\%$ of patients } \\
\hline \multicolumn{3}{|l|}{ No. of ED visits } \\
\hline 0 & 4.7 & $50.6^{*}$ \\
\hline 1 & 20.9 & 20.0 \\
\hline 2 & 23.3 & 10.6 \\
\hline$\geq 3$ & 51.2 & 18.8 \\
\hline Hospital admission in the past year, \% yes & 27.9 & 20.9 \\
\hline Past ICU admissions for asthma, \% yes & 22.1 & 24.4 \\
\hline Previous intubations/mechanical ventilation, \% yes & 14.0 & 18.6 \\
\hline $\begin{array}{l}\text { No. of ambulatory care visits in the previous year, } \\
\text { median (IQR) }\end{array}$ & $1(0,4)$ & $3(2,4)^{*}$ \\
\hline $\begin{array}{l}\text { Difficulty performing work or other activities as a result } \\
\text { of asthma in the past month, \% yes }\end{array}$ & ult $\quad 81.4$ & $49.4^{*}$ \\
\hline \multicolumn{3}{|l|}{ Days of disability due to asthma, median (IQR) } \\
\hline In the past year & $11(2,30)$ & $2(0,15)^{*}$ \\
\hline In the past month & $3(1,14)$ & $0(0,0)^{*}$ \\
\hline Regular inhaled corticosteroids, \% yes & 18.6 & $75.3^{*}$ \\
\hline $\begin{array}{l}\text { Oral corticosteroid use ( }>30 \text { days in the last year), } \\
\% \text { yes }\end{array}$ & 52.3 & 47.7 \\
\hline Long-acting $ß$ agonists, \% yes & 27.7 & 34.1 \\
\hline Oral theophylline, \% yes & 32.9 & $17.4^{*}$ \\
\hline Inhaled ipratropium bromide, \% yes & 34.5 & 31.8 \\
\hline Home nebulizer, \% yes & 79.1 & 75.3 \\
\hline Comorbidities, \% yes & 55.3 & 64.0 \\
\hline Acute respiratory illness, \% yes & 41.3 & $14.5^{*}$ \\
\hline Cardiovascular & 45.7 & 52.7 \\
\hline Psychiatric & 10.9 & 3.6 \\
\hline Other & 47.8 & 61.8 \\
\hline \multicolumn{3}{|l|}{ Smoking status, \% } \\
\hline Current & 14.0 & $3.5^{*}$ \\
\hline Past & 36.0 & 39.5 \\
\hline Never & 50.0 & 57.0 \\
\hline Passive smoking & 44.2 & 32.9 \\
\hline
\end{tabular}

$\mathrm{ED}=$ emergency department; $I \mathrm{ICU}=$ intensive care unit; $I \mathrm{QR}=$ median with interquartile.

${ }^{*} \mathrm{P}<0.05$ compared to emergency department patients (chi-square test for categorical variables and Mann-Whitney U-test for continuous variables). oral theophylline compared with the AC patients (32.9 vs $17.4 \%$, respectively; $\mathrm{P}=$ 0.031 ). ED patients were more likely to have acute respiratory illness (defined by the presence of a sore throat, rhinorrhea, sneezing, sputum production, or fever) than ambulatory care patients $(41.3 \mathrm{vs} 14.5 \%$, respectively; $\mathrm{P}=0.005)$. There was a higher rate of current smoking status among ED patients compared with AC patients (27.3 vs 8.1\%, respectively; $\mathrm{P}=0.03)$. The two groups did not differ regarding other characteristics in this category.

The data about being provided with a written asthma management plan and handling of MDI are shown in Table 3. Fifty-six percent of ED patients reported having an asthma attack action plan compared with only $29 \%$ of AC patients $(\mathrm{P}<0.001)$. Significantly more AC patients than ED patients used to increase or start steroid therapy when an attack was perceived (46.5 vs $20.9 \%$, respectively; $\mathrm{P}<0.001)$. Ninety-one percent of AC patients reported use of MDI medications compared to $75 \%$ of ED patients $(P=0.008)$. Significantly more AC patients than ED patients were able to perform all steps of an adequate MDI technique (50.0 vs 11.6\%, respectively; $\mathrm{P}<0.001$ ). Only $36.5 \%$ of AC patients compared with $65.9 \%$ of ED patients stopped medications without medical advice when they felt asthma was getting better $(\mathrm{P}<0.001)$. Fifty-one percent of AC patients vs 33\% of ED patients reported knowledge about factors triggering asthma $(P=0.02)$. Eighty-six percent of ED patients vs $63 \%$ of AC patients were interested in participating in an asthma education program $(\mathrm{P}=0.003)$.

The results of multivariate logistic regression analysis for different categories of vist frequency are presented in Table 4 . The history of hospital admissions in the previous year ( $\geq 3$ and $\geq 4$ ED visits in the last year) and use of regular inhaled corticosteroids were independently associated with frequent visits to the ED. 


\section{Discussion}

We compared the clinical characteristics of patients attending the ED adult for treatment of acute asthma exacerbation with those of patients attending an AC for nonurgent treatment of asthma in a large, tertiary care, university-affiliated hospital in the south of Brazil. We also determined factors associated with frequent visits to the ED in these two groups of patients.

There were no differences between groups regarding sex distribution or ethnic origin. It is worth noting that patients belonging to the AC group were older (mean age $52.8 \pm 15.7$ years) than those belonging to the ED group (38.4 \pm 18.3 years). A previous study (9) supported the association between younger age and multiple previous ED visits and nonadherence to regular treatment. However, the present study did not find any association between age and frequent visits to the ED in a multivariate logistic regression analysis $(\mathrm{P}$ $>0.05$ )

There were no differences between groups in socioeconomic status. Of interest is the fact that $53.5 \%$ of all the patients avoided using asthma medications due to cost concerns and that $66.5 \%$ of patients had a very low income level $(<\mathrm{R} \$ 12,000$ per annum, corresponding to approximately US\$4,000). It is worth noting that our institution provides care for the public health system patients without direct user fees. As a consequence, our study population is made up of people with lower income and sociocultural level. Asthma is more prevalent and severe among lower socioeconomic groups (10), and it is likely that our sample is biased toward the socially disadvantaged. Otherwise, the present study did not show any association between socioeconomic status and ED visit frequency for asthma care. Again, these results are restricted by the low-income level of patients attending our Hospital, making it more difficult to adequately control the effects of belonging to a higher socioeconomic status.

Compared to the patients attending the $\mathrm{ED}$, patients attending the asthma outpatient clinic were more likely to report previous ambulatory care visits for asthma treatment, to be taking regular inhaled corticosteroids, to increase or to initiate steroid therapy when an attack was perceived, to have adequate MDI technique, to take regularly the prescribed medications even when their asthma was getting better, and to have knowledge about asthma triggers. Moreover, only 17\% of the AC patients took oral xanthine as a regular medication compared to $33 \%$ of the ED patients, and only $3.5 \%$ of the AC patients are current smokers compared to $14.0 \%$ of the ED patients. These findings reflect the higher level of asthma education in the group of patients attending the AC. By contrast, only $29.1 \%$ of the AC patients reported having a written asthma attack action plan compared to $55.8 \%$ of the ED patients.

Table 3. Asthma management plan and use of a metered-dose inhaler.

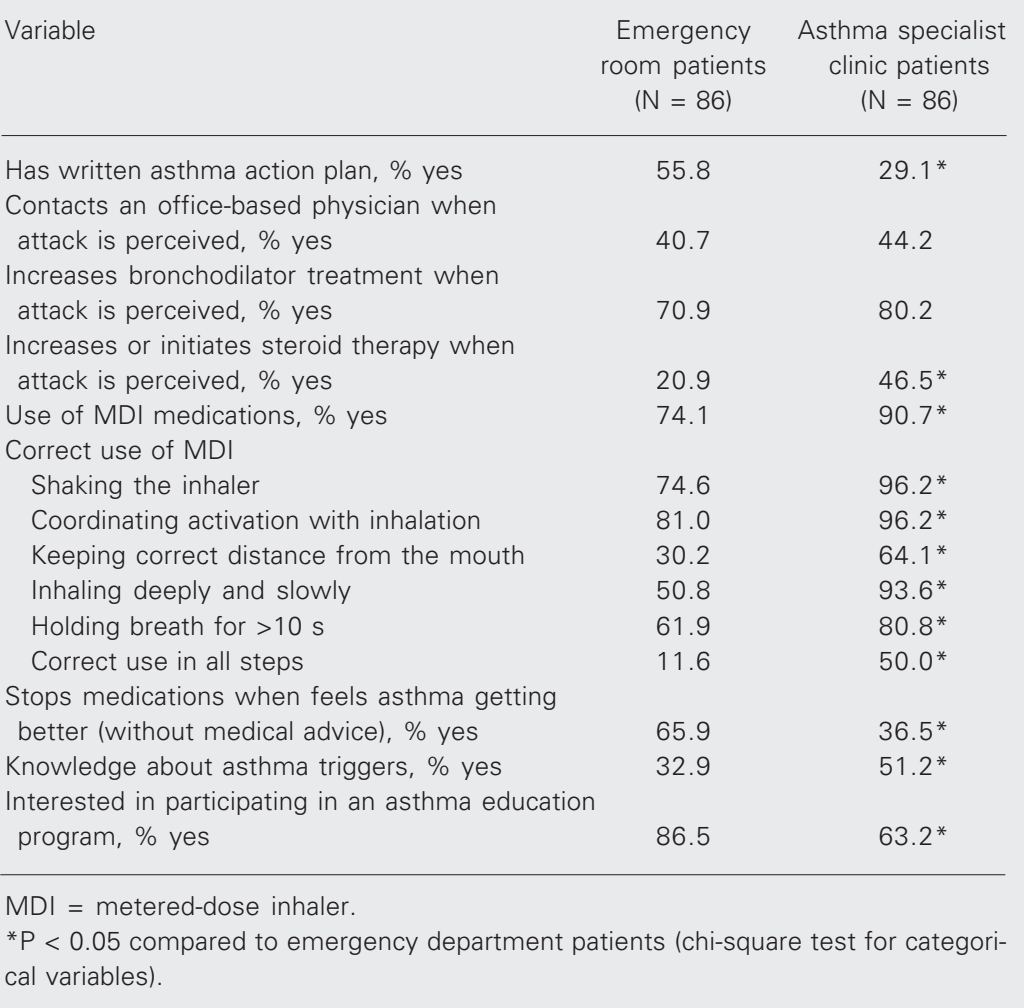


Previous studies have demonstrated that the use of a written action plan may reduce asthma morbidity, as indicated by the significant effect of providing such an action plan to the patients on the rate of both hospital admissions and ED visits (11-13). However, in our study we found that the frequency of visits to the ED was higher in the urgent care group compared to the routine care group ( $\mathrm{P}$ $<0.001)$. This paradoxical finding could be explained by the low standard of self-management in spite of having a written action plan and the actual behavior exhibited by the ED patients during an asthma attack. Although lacking a written action plan, under routine care patients were more likely to increase or to initiate steroid therapy when their asthma got worse.

Our data show that significantly more AC patients than ED patients used the MDI

\begin{tabular}{|c|c|c|c|}
\hline Variable & OR & $95 \% \mathrm{Cl}$ & $P$ value \\
\hline \multicolumn{4}{|c|}{ Hospital admission in previous year } \\
\hline$\geq 2$ ED visits in the last year & 2.35 & $0.69-8.00$ & 0.17 \\
\hline$\geq 3$ ED visits in the last year & 4.00 & $1.16-13.89$ & 0.03 \\
\hline$\geq 4$ ED visits in the last year & 5.38 & $1.55-18.52$ & 0.008 \\
\hline \multicolumn{4}{|c|}{ Regular use of inhaled corticosteroids } \\
\hline$\geq 2$ ED visits in the last year & 0.30 & $0.10-0.85$ & 0.02 \\
\hline$\geq 3 \mathrm{ED}$ visits in the last year & 0.27 & $0.08-0.86$ & 0.03 \\
\hline$\geq 4$ ED visits in the last year & 0.30 & $0.09-1.00$ & 0.05 \\
\hline \multicolumn{4}{|c|}{$\begin{array}{l}\text { Had difficulty performing work or other } \\
\text { activities as a result of asthma in the past month }\end{array}$} \\
\hline$\geq 2$ ED visits in the last year & 1.01 & $0.99-1.03$ & 0.08 \\
\hline$\geq 3 \mathrm{ED}$ visits in the last year & 1.01 & $1.00-1.02$ & 0.05 \\
\hline$\geq 4$ ED visits in the last year & 1.01 & 0.99-1.02 & 0.08 \\
\hline \multicolumn{4}{|l|}{ Home nebulizer } \\
\hline$\geq 2$ ED visits in the last year & 2.58 & $0.89-7.46$ & 0.08 \\
\hline$\geq 3$ ED visits in the last year & 2.67 & $0.75-9.52$ & 0.13 \\
\hline$\geq 4$ ED visits in the last year & 2.11 & $0.56-7.69$ & 0.26 \\
\hline \multicolumn{4}{|l|}{ Age } \\
\hline$\geq 2$ ED visits in the last year & 1.00 & $0.98-1.03$ & 0.89 \\
\hline$\geq 3 \mathrm{ED}$ visits in the last year & 1.02 & $0.96-1.01$ & 0.19 \\
\hline$\geq 4$ ED visits in the last year & 1.02 & $0.99-1.05$ & 0.33 \\
\hline \multicolumn{4}{|l|}{ Correct use of MDI (all steps) } \\
\hline$\geq 2$ ED visits in the last year & 0.90 & $0.34-2.38$ & 0.83 \\
\hline$\geq 3 \mathrm{ED}$ visits in the last year & 0.64 & $0.21-1.98$ & 0.44 \\
\hline$\geq 4$ ED visits in the last year & 0.87 & $0.27-2.76$ & 0.81 \\
\hline
\end{tabular}

$\mathrm{ED}=$ emergency department; $\mathrm{MDI}=$ metered-dose inhaler; $\mathrm{OD}=$ odds ratio . technique adequately in all steps (50.0 vs $11.6 \% ; \mathrm{P}<0.001)$. This reflects the fact that asthma education level was greater in the AC group compared to the ED group. By contrast, Hanania et al. (5) reported that significantly more AC patients than ED patients had adequate MDI technique, and with a higher frequency of correct use (100 vs 82\%; $\mathrm{P}<$ $0.05)$. This observation suggests that even the patients of the ambulatory care clinic of our Hospital should be better trained in the MDI technique.

Our study did not control the severity of the airflow obstruction that caused patients to seek the ED. However, a previous study (14) showed that only $13 \%$ of the patients who appeared at the adult ED of our Hospital with an asthma attack had a forced expiratory volume in the 1 st minute $\left(\mathrm{FEV}_{1}\right)$ above $50 \%$ of the predicted value. Thus, we believe that most of the patients attending our ED are subjects with moderate to severe acute asthma.

Compared to the patients attending the AC, ED patients were more likely to have difficulty performing work or other activities as a result of asthma, to have more days of disability in the previous year and month and to have more acute respiratory illnesses. However, the patients in the AC group were more likely than the ED group to have attended scheduled follow-up visits during the previous year. These results suggest that the patients dependent on ED care are more likely to suffer more severe disease as a consequence of their inappropriate health care utilization behavior. Other measures of asthma severity such as hospital admissions in the past year, past ICU admissions for asthma and previous intubation/mechanical ventilation did not differ between groups.

The present results show that a substantial proportion of patients are frequent visitors to the ED. To determine the factors responsible for this behavior, we compared the characteristics of patients who were occasional visitors with those of patients 
who were frequent visitors. The results of the multivariate analysis for different categories of visit frequency identified two variables (history of hospital admission in the previous year and regular use of inhaled corticosteroids), which were independently associated with frequent visits to the ED.

Previous hospitalizations are a marker of asthma severity and in our study were associated with frequent ED visits. Similarly, recent studies reported an association between repeated ED visits and previous hospitalization $(2,11,15)$. In another study $(10)$, a prior admission to a hospital did not prove to be so strong a predictor of frequent ED visits for relapse within eight weeks after an acute asthma exacerbation in adults.

Inhaled corticosteroids are the most effective medications currently available to treat symptomatic asthma. They are considered to be the first-line therapy for patients with daily asthma symptoms $(16,17)$. A previous study demonstrated that inhaled corticosteroids can prevent exacerbations of asthma that could lead to hospitalizations (18). In our study, the regular use of inhaled corticosteroids was associated with a low frequency of ED visits. In most regions of Brazil, not all the asthma medications for the treatment of outpatients are provided by the public health care system. Economic factors could explain the infrequent use of regular inhaled corticosteroids (only $46.5 \%$ of all patients), but we did not find differences in the income level when comparing frequent ED visitors with occasional ED visitors. Moreover, we found that $76 \%$ of ambulatory patients used regular inhaled corticosteroids compared to only $19 \%$ of ED patients, with no difference in income level between groups. As previously shown, these findings lead to the speculation that low income may be a marker for sub-optimal health care utilization rather than a cause of it (5).

Our study is restricted by its crosssectional design, which limits our conclusions to correlational observations rather than providing the identification of causal processes.

This study suggests that ED patients should be considered an important target for asthma education. Provision of self-managing education in the ED and facilitating the referral and access to ambulatory care might serve to reduce asthma morbidity.

\section{Acknowledgments}

We are indebted to Vânia Naomi Hirakata for the statistical analyses, and to the medical, administrative and nursing staff of the Emergency Department of Hospital de Clínicas de Porto Alegre for their collaboration.

\section{References}

1. Smith DH, Weiss K \& Sullivan SD (2000). Epidemiology and costs af acute asthma. In: Hall JB, Corbridge TC, Rodrigo C \& Rodrigo GJ (Editors), Acute Asthma: Assessment and Management. McGrawHill, New York, 1-10.

2. Eisner MD, Katz PP, Yelin EH, Shiboski SC \& Blanc PD (2001). Risk factors for hospitalization among adults with asthma: the influence of sociodemographic factors and asthma severity. Respiratory Research, 2: 53-60.

3. Weber EJ, Silverman RA, Callaham ML, Pollack CV, Woodruff PG, Clark S \& Camargo Jr CA (2002). A prospective multicenter study of factors associated with hospital admission among adults with acute asthma. American Journal of Medicine, 113: 371-378.

4. Cowie RL, Underwood MF, Revitt SG \& Field SK (2001). Predicting emergency department utilization in adults with asthma: a cohort study. Journal of Asthma, 38: 179-184.

5. Hanania NA, David-Wang A, Kesten S \& Chapman KR (1997). Factors associated with emergency department dependence of patients with asthma. Chest, 111: 290-295.

6. Dalcin PTR, Fernandes AK, Mallmann F, Nogueira FL, Steinhorst AMP, Machado FJ, Raymundi MG, Saucedo D, Ávila EM \& MennaBarreto SS (2002). Characteristics of patients with acute asthma in the emergency department in Porto Alegre, Brazil: frequent visitors versus occasional visitors. American Journal of Respiratory and Critical Care Medicine, 165 (Suppl): A120.

7. Zeiger RS, Heller S, Mellon MH, Wald J, Falkoff R \& Schatz M (1991). Facilitated referral to asthma specialist reduces relapses in 
asthma emergency room visits. Journal of Allergy and Clinical Immunology, 87: 1160-1168.

8. American Thoracic Society (1987). Standards for the diagnosis and care of patients with chronic obstructive pulmonary disease (COPD) and asthma. American Review of Respiratory Disease, 136: 225244.

9. Schmaling KB, Afari N \& Blume AW (1998). Predictors of treatment adherence among asthma patients in the emergency department. Journal of Asthma, 35: 631-636.

10. McCarren M, McDermott MF, Zalenski RJ, Jovanovic B, Marder D, Murphy DG, Kampe LM, Misiewicz VM \& Rydman RJ (1998). Prediction of relapse within eight weeks after an acute asthma exacerbation in adults. Journal of Clinical Epidemiology, 51: 107118.

11. Adams RJ, Smith BJ \& Ruffin RE (2000). Factors associated with hospital admissions and repeat emergency department visits for adults with asthma. Thorax, 55: 566-573.

12. Brooks WB, Jordan JS, Divine GW, Smith KS \& Neelon FA (1990). The impact of psychologic factors on measurement of functional status. Assessment of the sickness impact profile. Medicine Care, 28: 793-804.

13. Osman LM, Calder C, Godden DJ, Friend JA, McKenzie L, Legge
JS \& Douglas JG (2002). A randomised trial of self-management planning for adult patients admitted to hospital with acute asthma. Thorax, 57: 869-874.

14. Mallmann F, Fernandes AK, Avila EM, Nogueira FL, Steinhorst AM, Saucedo DZ, Machado FJ, Raymundi MG, Dalcin PT \& Menna Barreto SS (2002). Early prediction of poor outcome in patients with acute asthma in the emergency room. Brazilian Journal of Medical and Biological Research, 35: 39-47.

15. Olopade CO, Alikakos Z, Abubaker J \& Rubinstein IR (1997). Characteristics of predominantly nonwhite patients with frequent hospitalizations for acute asthma in Chicago. Journal of Asthma, 34: 243-248.

16. O'Byrne PM \& Hargreave FE (2001). Role of inhaled corticosteroids. In: FitzGerald JM, Ernst P, Boulet LP \& O’Byrne PM (Editors), Evidence-Based Asthma Management. BC Decker Inc., Hamilton, Ontario, Canada, 183-197.

17. Zahorik KJ \& Busse WW (2000). Chronic asthma. In: Hall JB, Corbridge TC, Rodrigo C \& Rodrigo GJ (Editors), Acute Asthma. Assessment and Management. McGraw-Hill, New York, 323-350.

18. Sin DD \& Man SF (2002). Low-dose inhaled corticosteroid therapy and risk of emergency department visits for asthma. Archives of Internal Medicine, 162: 1591-1595. 